\title{
What Has Changed? Parents and Community Members' Perceptions on an Education Intervention for Girls in the Slums of Nairobi
}

\author{
Benta A. Abuya, Moses Ngware, Milka Nyariro \\ African Population and Health Research Center (APHRC), APHRC Campus, Nairobi, Kenya \\ Email: atienoa6@gmail.com, mngware@aphrc.org, milkanyariro@gmail.com
}

Received 29 June 2015; accepted 14 September 2015; published 17 September 2015

Copyright (C) 2015 by authors and Scientific Research Publishing Inc.

This work is licensed under the Creative Commons Attribution International License (CC BY). http://creativecommons.org/licenses/by/4.0/

(c) (i) Open Access

\begin{abstract}
The objective of the paper is to examine reflections of parents and community members with a community based intervention for girls aged 12 - 19 years in the slums of Nairobi. The intervention involved mentoring in life skills and after school support for girls; and, parental counselling on supporting girls' education. This paper is motivated by the need to identify from the perspective of parents and community members, what has changed in regard to the education and social lives of the girls, both at school and within the households as a result of one-year exposure to an intervention. Data were collected using in-depth interviews and focus group discussions (FGDs) during the qualitative midterm survey conducted in Korogocho and Viwandani slums, in Nairobi, Kenya. Results show that parents and community gatekeepers' generally have a positive experience with the outcome of the intervention one year after the onset of the intervention. In conclusion, the knowledge gained by the beneficiaries is gradually leading to an empowerment process within the urban informal settlements, as both girls and their parents become advocates of the program.
\end{abstract}

\section{Keywords}

Girls, Urban, Parents, Community, Intervention, Advocates

\section{Introduction}

"A 90-year-old woman is going to school to learn skills that she never had the opportunity to acquire when she was younger" quotes one of the local dailies in Kenya. This except sums up the importance with which education is held by a one-time girl who is currently ninety years old and did not have an opportunity to go to school.

How to cite this paper: Abuya, B.A., Ngware, M. and Nyariro, M. (2015) What Has Changed? Parents and Community Members' Perceptions on an Education Intervention for Girls in the Slums of Nairobi. Open Journal of Social Sciences, 3, 209-222. http://dx.doi.org/10.4236/iss.2015.39029 
The plight of this 90 years old reinforces the fact that access to school for all children remains an important milestone that countries like Kenya have to continue to strive for. Particularly for girls, access to school remains critical [1]. According to these authors, in many low income countries access to basic education is far from being realized. However, Kenya has made great strides in its quest to provide education for a vast majority of children. For instance, free primary education program increased in enrolment from $8.8 \mathrm{M}$ (4.5 male; 4.3 female) in 2011 to 10.1 million (5.1 million and 5 million, male and female, respectively) in 2013 [2]. However, education of girls remains critical, and scholars continue to agree that there is an immense benefit that accrues to girls and their respective countries when they get an education. These benefits include small family size, delaying marriage, improved child health and economic benefits to a woman, her family, and community [3]. However, in addition, new thinking on education also posits that education alone is not enough to achieve "empowerment", and that girls need critical thinking skills as well as changes in their enabling environment [4].

Despite the documentation of the benefits that accrue to girls as a result of their education, evidence shows that participation rates are much lower at secondary levels, even as many more of these girls complete primary education [5]. In particular, the low participation rate is evidenced among girls and disadvantaged groups, including those living in the informal settlements in Kenya [6]. Research evidence does suggest that in Kenya, many disadvantaged poor girls are not making a transition to secondary schools and are therefore missing out on the opportunities that secondary education offers [6] [7]. With increased access into the primary schools, it was important to begin to focus on transition to secondary school as the next schooling stage for girls. Therefore, ensuring that girls complete grade 8 and join secondary school becomes very critical [8]. The issues of primary school completion and transition becomes critical because recent research evidence by APHRC shows that $47 \%$ of pupils in the urban informal settlements attend informal private schools for the poor that are poorly equipped, and about $60 \%$ of teachers are not trained [9]. Despite the fact that the government of Kenya has achieved a primary school gross enrolment rate of above $100 \%$ in primary schools mainly due to the presence of a Free Primary Education program [10], transition to secondary education is lower (58.6\%) among pupils in slums compared to those in non-slums (87.5\%) [11].

Progress is being made, but girls and women continue to be disadvantaged and particularly girls who live in marginalized areas. Disadvantaged adolescent girls are excluded from participating in mainstream education and programs targeting the youth. Moreover, when girls are marginalized, they are often illiterate, are prone to early marriage and early childbearing, and are in some instances living away from their parents in marginalized rural or urban slums [12]. In particular, girls who attend school in the slums undergo challenges that inhibit their ability to make a transition to secondary school [13]. Therefore, primary schooling and subsequent transition to secondary school for girls in the urban informal settlements remain a challenge that needs further investigation. It was against this background that this study sought to establish parental and community members' perceptions regarding what has changed since the onset of the education intervention initiated for girls in the slums of Nairobi. This paper sought to answer the following question: What has changed? Parents and community members' perceptions on an education intervention for girls in the slums of Nairobi.

\subsection{Context of the Study}

This study was nested in the Nairobi Urban Health Demographic System (NUHDSS), which has been operating since 2002. The NUHDSS is a longitudinal platform in two slums in Nairobi-Korogocho and Viwandanimanaged by the African Population and Health Research Center (APHRC). These two slum areas are densely populated (63,318 and 52,583 inhabitants per square km, respectively), and are characterized by poor housing, lack of basic infrastructure, violence, insecurity, high unemployment rates, and poor health indicators [14]-[16]. Korogocho is an informal settlement in Ruaraka Sub-County, occupying an area of $0.9 \mathrm{~km}^{2}$ within Kasarani Division, and approximately $11 \mathrm{~km}$ from Nairobi's central business district. Viwandani is an informal settlement in Makadara Sub-County, occupying $5.7 \mathrm{~km}^{2}$ in the industrial part of Nairobi, about $7 \mathrm{~km}$ from the city center.

\subsection{The Intervention}

The study deployed a multi-pronged education intervention approach: 1) after-school support and mentoring for girls, 2) a subsidized primary to secondary school transition; and 3) a parental guidance and counselling.

After-school homework support and mentoring: The aim of this component of the intervention was to increase the opportunity to learn for girls and therefore enhance their transition to secondary school. This component did 
this in two ways: First, is to increase the instructional time among poor performing children by providing girls with space within the community, and mentors to oversee their homework; and second, to provide the opportunity for at risk children to get support through community-based positive role models. Girls came into these centers and had the opportunity to undertake their homework in English and Math. Support with homework was also reinforced with mentoring in life skills, which entailed girls being taken through a curriculum of skills that inculcated in them the necessary skills to be able to survive puberty. After-school support and life skills mentoring were provided to girls aged 12 to 19 years and enrolled in grades six, seven and eight. Girls were exposed to after-school support with homework in numeracy and literacy for two hours once a week while they were exposed to mentoring for one hour once a month, after the initial six weeks where they were exposed to one hour of mentoring every two weeks.

Primary-to-secondary transition subsidy: Subsidizing the cost of secondary school first entry is a sub-component of the intervention that rewards those girls who were recruited in the program, consistently participated, and attained at least 250 out of 500 marks in Kenya Certificate of Primary Education (KCPE) done at the end of grade 8 - end of primary school cycle.

Parental and community intervention: This component of the intervention targets parents of girls aged 12 - 19 years in informal settings in order to provide support for education and schooling of girls who are at risk of not completing primary or secondary, or not making a transition to secondary school. The intervention is expected to impact on the lives of these parents positively, thereby empowering them to be able to positively impact on the lives of their daughters. This was through guiding and counselling parents on the kind of social, schooling and educational support they can provide to girls. This included but was not limited to providing and obtaining information on minimizing the amount of time that girls spent on household chores. This aimed at ensuring that parents support girls with homework, release the girls to attend the after-school support with homework sessions, cooperate with the volunteers and mentors to help the girls. Besides, they will cooperate with the teachers to track the girls' performance in school, and encourage the parents to attend sensitization sessions with girls. The counselors use the counseling guides to carry out the guidance and counselling sessions with parents. The parental guidance and counselling sessions are held once every quarter.

\section{Methodology}

\subsection{Study Population}

The midterm evaluation involved tracking girls who were already in the program, and recruited during baseline conducted in June 2013. Recruitment during the baseline included all households with girls aged between 12 and 19 years and in grades six, seven and eight in Korogocho and Viwandani within the NUHDSS. A list with 1271 girls who had been recruited at baseline was updated during midterm data collection. The design of the pilot project is quasi-experimental, focusing on 2 treatments and 1 comparison group in each of the urban informal settlements. The two treatment and one the comparison group were randomly assigned to these enumeration areas. Treatment group 1 was exposed to afterschool support with homework and community-based intervention; while treatment group 2 is exposed to afterschool support with homework only; the comparison group receives no intervention. During midterm, 1181 (93\%) girls had their schooling history information updated in order to establish the schooling status of all girls who had been enrolled in the program. Those whose information was not updated had either migrated out of the study sites or their households could not be traced. Data was collected using focus group discussions (FGDs) and in-depth interviews (IDIs). Parents of the girls in the program were mobilized to participate in the focus group discussions. In-depth interviews were conducted with the elders and community leaders. Six FGDs were conducted with parents (2 in Treatment 1 (T1), 2 in Treatment 2 (T2) and 2 in Control (C), In addition, FGDs, six in-depth interviews were conducted with community leaders and village elders. Moreover, there were 65 parents who participated in the FGDs and 6 community leaders. Data collected were narratives from the in-depth interviews and FGDs. For this paper, the narratives come from a follow-up of the same parents who had been parents whose narratives had been collected at baseline.

\subsection{Selection of Parents and Community Leaders}

A list of parents in the three treatment zones (T1, T2 and C) were generated in each site, categorized by gender and a random selection of 18 parents was made from each category to constitute either a male or a female only 
FGD in each site. The random selection was to ensure representation across gender and site. The expected categories of FGDs were three male and three female. However, at the time of data collection, male parents opted to send their spouses to represent them. As a result there were three mixed gender FGDs in Viwandani and three female only FGDs in Korogocho. We recognized that the mixed gender are limited due to the social-cultural dynamics and power relations that come into play during discussions between men and women. We controlled for these differences by giving ample time to each participant, and each sex to speak about the issues around keeping girls in schools. In this way, we tried to minimize the bias that could have been introduced by both men and women being participants in the same FGD Therefore, the moderators explored both the female and the male participants' perceptions in regard to their daughters' education. In regard to the selection of community leaders, chiefs and the village elders in both Korogocho and Viwandani were included into the study. It was important to get the perceptions of chiefs and village elders because of their strategic importance as the community gatekeepers in both Korogocho and Viwandani.

\subsection{Data Collection}

Data collection approval was through the Institutional Review Board at Kenya Medical Research Institute (KEMRI). The main method for data collection was the use of focus group discussions and IDIs. FGDs were conducted by a trained moderator and an assistant moderator between $22^{\text {nd }}$ May and $1^{\text {st }}$ June. During training the FIs actively participated in order to understand the questions, and how to ask the questions once they were in the field. In so doing, both the research team and the FIs were able to reflect on the questions in the protocols. Role plays were also conducted during training to simulate the research process, giving the FIs a chance to be able to reflect on the possible outcomes during the actual fieldwork. The FGD and IDIs were conducted in specific sites already identified within the respective communities. The FGDs lasted a minimum of one to one and a half hours, while the IDIs lasted on average 45 minutes. All interviews were tape recorded for later transcription and analysis. The discussions began with a short conversation to establish rapport, and to have a formal introduction by all the participants, as well as the moderator and assistant moderator. The moderator led the discussion based on a series of questions in the protocol FGD (see Table 1), and the in-depth interview guide (see Table 2) which were designed to investigate parental and community members' perceptions of what may have changed since the onset of the intervention. The distribution of the FGD participants is shown in Table 3.

\subsection{Analytical Strategy}

We used NVivo software to facilitate storage and manipulation of the data. Analysis of the qualitative data involved generation of codes both inductively and deductively. The deductive coding was largely based on the research questions guiding the midterm study, while inductive coding involved relevant concepts that emerged "bottom up from the data". These codes were mainly generated after listening to voice records and also reading

Table 1. Focus discussion guide.

\section{Focus group discussion guide}

1) To investigate parental understanding of their role and that of the community towards the education of their daughters.

2) To understand the challenges that affect girls' education in the two urban informal settlements where an education intervention is being implemented.

1) Give an account of your daughter(s) school attendance to date.

3) In your opinion, what do you think is the role of this community in keeping the girls in school?

a) In your opinion what do you expect the community to do differently in order to improve education for your daughters' in this community?

5) In what ways has your daughter benefitted from other interventions in this community, if any?
2) What in your view has encouraged you to keep your daughter in school?

a) What issues have you been found to be a challenge if any?

b) How have you attempted to solve the challenges?

4) What has been your role in your daughters' schooling so far a) In what other ways do you think you can be of help to your daughter's schooling?

6) What is your expectation of your daughter being that she is involved in this program?

7) What changes have you been able to observe in the past one year? 
Table 2. The in-depth interview guide questions.

\section{In-depth interview protocol}

1) To investigate the community gatekeepers understanding of their role and that of the community towards the education of girls.

2) To understand the challenges that affect girls' education in the two urban informal settlements where an education intervention is being implemented.

1) What is your role as a village elder in this community?

3) In your opinion, what do you think is your role as [village elder; chief] in keeping girls in school?

a) What are you doing now and what do you hope to do differently?

5) What are some of the challenges that affect girls in this community from attending and completing school?

a) How have you as a community tackled some of these challenges?

7) In the last 12 months, what are some of the changes that were noticed on girls' education in this community?
2) What is your general understanding of children's education in this community?

4) In your opinion, what is the role of this community in keeping the girls in school?

a) In your opinion, what do you expect the community to do differently in order to improve education of girls in this community?

6) In what ways have girls in this community benefitted from other interventions, if any?

Table 3. The distribution of FGDs by site.

\begin{tabular}{ccc}
\hline Study site & Intervention type & Number \\
\hline \multirow{2}{*}{ Korogocho } & Treatment 1 & 12 \\
& Treatment 2 & 11 \\
\hline \multirow{2}{*}{ Viwandani } & Control & 08 \\
& Treatment 1 & 15 \\
& Treatment 2 & 12 \\
\hline
\end{tabular}

the first set of transcripts. We generated codes from the research question: What has changed? Parents and community members' perceptions with an education intervention for girls in the slums of Nairobi. A review of the transcripts enabled us to identify the relevant codes that would emerge from the chunks of data, looking either for phrases that occurred frequently as affecting the education of girls, and the thinking of the parents and community members in the slum context—either Korogocho and Viwandani-while having an eye for unique occurrences within the data (Miles \& Huberman, 1994). The first reading of transcripts was to familiarize with the responses and to gain insights and clues as to what was contained in the data and thereby enrich the inductive codes. In reading the transcripts, we were looking out for the issues and concepts that characterized the dynamics of how parents and community members' perceptions show that the intervention is taking root in the urban informal settlements. In the subsequent readings, we were looking for the ideas, phrases, concepts, and words that were most pronounced in the data; for example, outcomes of the intervention, performance, communication, motivation, and concerted effort. In so doing, the initial codes were those that had occurred severally in the data, thereby we were able to pick these categories that were saturated in the data. Subsequently, the initial codes allowed us to tentatively group the data, make descriptions, and extract quotes from the data chunks to support the emerging categories, based on the patterns and interpretations given to a code or sets of codes.

\section{Results}

This section highlights parental and community reflections with the education intervention one year after the program was rolled out in two informal urban settlements in Nairobi, Kenya. Reflections were narrated in FGDs and IDIs with parents of girls in grades 7 and 8, and community gatekeepers in both Korogocho and Viwandani. In this section, we highlight community gatekeepers' and parents reflections on the outcomes of the intervention. The main thematic areas highlighted in this section of the challenges affecting girls' education include: improvement in the general performance of girls; improved communication; increased knowledge on numeracy and lite- 
racy motivation and positive attitude; trickling effects of life-skills; and concerted effort in support of girls.

\subsection{Outcomes of the Intervention}

The community gatekeepers in this study were the chiefs of both Korogocho and Viwandani and their respective elders, who assist them in running the day to day activities in the two sites. A chief is the senior most government administrative officer in-charge of a geographical area called "Location" that is sub divided into several sub-locations or villages headed by an Assistant Chief. Chiefs represent the Central government in all development activities, including education, taking place in their area of jurisdiction. To discharge their duties, they are supported by elders who are nominated by the village members in the new system of devolved government. The parental perceptions are from parents of girls in classes 7, and 8 who are part of the study sample in 2014. The main purpose of this subsection is to document the immediate impacts of the education intervention from the narratives of parents and community members, one year after the onset of the intervention. This is being done from the reflections of the parents whose daughters are in the program, and from interviews with the chiefs and village elders.

\subsection{Improvement in the General Performance of Girls}

One of the intended outcomes of this intervention was to improve the performance of girls in literacy and numeracy. The underlying assumption was that girls who come from poor backgrounds such as Korogocho and Viwandani lose out on the opportunity to learn as a result of inadequate time to study in school, and inadequate parental support at home. Lack of parental support was, in part, due to parents' unavailability to help with homework and girls' higher burden of domestic work as compared to their male peers. Inadequate time spent on school work rendered girls unable to perform well in their studies. The reflections of the community gatekeepers give a ray of hope in the two communities of Korogocho and Viwandani. For instance, the community gatekeepers explain that girls are beginning to improve generally in their schoolwork. The community gatekeepers perceive improvement in terms of the scores of children in Math and English. The improvement is a result of parents beginning to give girls time to read, do their homework, and listen to their daughters more. As a result of all this, girls in the program are becoming more confident and are able to compete favorably with boys. The chief from Koch explains:

... I would say that girls are no longer weak like people used to assume. They have shown through their performance... Parents never used to give the girls time to revise and read but now the parents are actually listening to girls... I have seen girls do very well and even compete with the boys... Now we are seeing girls getting 380 and the boys do not even get that. Girls have realized they are capable of doing well just like the boys...

Parents in Viwandani were of the opinion that the afterschool support sessions have gone a long way to improve girls' ability to improve in school. Some parents shared the dramatic improvement of their daughters from almost being at the bottom of the class to being top of their classes. A female parent from Viwandani while expressing the views of fellow parents said this:

Since the beginning of the Saturday tuition ${ }^{1}$, I have seen a lot of improvement with my child... Lydia who is in class seven in the past was number 30 but this term she was number 3 and I am so grateful, even the way that she used to speak is not the way she does right now. Even her behavior is okay since she started that tuition.

The community gatekeepers also lauded the network of the volunteers in the community who have been brought together as a result of the partnership... who have intensified the after-school support sessions in pursuit of excellence in Mathematics and English. In the views of the community gatekeepers, and particularly the chiefs, the mode of the after-school support is unique. The chief of Korogocho had this to say:

Girls do their homework and are assisted in English and mathematics during the weekends... We have mentorship and after-school coaching which helps the girls to do their homework and also to develop a lik-

\footnotetext{
${ }^{1}$ Parents referred to the afterschool support as tuition because this is the way they understand any additional support to children. However,
} the afterschool support sessions are not tuition they are sessions in which girls are provided with space and supported to do their homework. 
ing to the subjects... like mathematics and English. These are subjects that girls did not like before... In this community, we have community teachers who are volunteering to teach them during weekends, holidays and after-school to encourage them to have that need of passing the exams. So, we have done it differently by coaching them in the evening or weekends...

In Viwandani, the chief underscored their focus on continued partnership with the parents as government representatives. They have internalized their role which is to constantly sensitize the parents, community members so that they can work closely with other government departments to ensure that girls attend school. In so doing, the community can begin to chip away at some of the challenges that plague girls' education. This is what the Viwandani chief said, "... what we are supposed to do is to keep on encouraging them (meaning parents and community members) to deal closely with the other departments..."

Parents in Viwandani also underscored the importance of the after-school support sessions, which they said had inculcated into the girls a sense of commitment and hard work. Girls would go for their studies in school and thereafter, proceed to attend the afternoon sessions. Girls became occupied with the after-school support sessions and there was hardly time to loiter around in the community. A parent in Viwandani who was representing Treatment site had this to say:

... I see that they have been helped... there are those who are in the schools for tuition now and they will leave at $1 \mathrm{pm}$, in the afternoon they should not be loitering... but because of that tuition (meaning after-school support with homework) they are occupied. So, I see that they have been helped by being committed...

One year after the onset of the intervention, community leaders report that parents are counselling fellow parents in the community and motivating them to take their daughters to school. This is one very important pointer, towards sustainability and scale up of the program. For instance, in a scale up project, the parents who had undergone the counselling sessions, and internalized, can be the facilitators of the parental sensitization component. This is what the chief of Koch had this to say:

... They (meaning parents) also have their own meetings either in groups at the village level to discuss parents who are in one way or the other unable to take girls to school or those who do not want to take girls to school. So, they warn them, encourage them and tell them what the policy of the government is...

Parents while reinforcing the observations made by the community gate keepers, explained that they have come to realize that their responsibility entails making sure that girls improve in their studies, by making constant follow-up with their daughters and the teachers. Making constant follow-ups with teachers was to ensure that the teachers are teaching, and girls are attending classes and learning. During the baseline, parents had emphasized on girls' school attendance, timely home return from school, and completion of their school work. Whereas the follow-up was evident in Korogocho at baseline, the emphasis on following up with teachers to ensure that they were teaching, and girls were learning was evident in both treatment enumeration areas of Korogocho and Viwandani a year after the start of the intervention. This is what a parent attending a female FGD in Korogocho in a treatment zone said:

Follow up your child to know, what the teacher taught, the homework the teacher gave her... then sit to do homework. Check what the teacher is teaching your child, and if you don't understand anything, go to the school and see the teacher and sit and talk and agree...

Likewise the parents in the treatment zone in Viwandani recognized the general improvement of girls in the exams done at school level, in addition to being aware of the happenings within their surroundings. The female parent in an FGD explained, if she sees anything bad "... she comes and tells me. So, I see that these teachers are teaching them very well. And even in exams, last term she did very well. She got good marks and was in a good position."

Moreover, parents in Viwandani noted some improvements in mathematics and literacy as a result of the after-school support with homework. The parents in Viwandani explained that girls are constantly improving in mathematics and reading. This is the excerpt from a female parent attending an FGD representing parents in treatment 1 zone in Viwandani explaining the progress in math and reading:

... Math was stressing her, but now when she comes home from school, she does her math well and, I do 
not even see her asking the one who is in secondary school. She picks her books and does it on her own... I can see that the child is doing well; she used to have reading problems. If you told her to read a sentence she would have difficulties but now she has improved and can read.

\subsection{Improved Communication}

At the baseline, parents and community elders were of the opinion that schools could not do it alone in respect of girls' education. Schools needed the support of the other stakeholders-parents and community members. At baseline parents, as members of the community proposed a collaborative model involving schools, teachers, girls, and the communities around the schools. Both parents and community stakeholders thought that a communication model—“community-communication-knowledge”-would be ideal in forging collective responsibility towards girls' education. The key message from the parents pointed to the importance of communication among each of the stakeholders who are engaged with girls' education. Parental narratives at midterm underscored the importance of communication between parents and their daughters in the household. The importance lies in improving the flow of information between parents and their daughters, thereby enhancing girls' school performance. It would also seem that parent to girl communication in the household completes the communication model described by parents at baseline. The importance of communication was a common-thread throughout the discussions with parents in both treatment zones of Korogocho and Viwandani.

Moreover, improvement in communication was noted several months after the start of the intervention in the process of the monitoring. At midterm, parents, particularly in the Treatment 1, who receive both the afterschool support and the parental counseling component, described a process that has enabled them to feel empowered, and to effectively communicate with their daughters. In addition, parents, have been able to openly talk to their daughters, and avoid being harsh to their daughters, a phenomenon that was pushing their daughters farther away from the parents. The consequence of the harshness was that girls were continually missing out on the critical parental warmth and support. This is a representation of what parents as members of the Korogocho community thought in regard to the role that communication has played in making them effective parents, enabling them to play a critical role in the lives of their daughters in respect to their schooling. A parent attending an FGD in Treatment 1 in Korogocho had this to say:

... Used to be very harsh and all the time I used to quarrel them... Having been taught here, I discovered that I was going wrong. So, when she goes to school her school marks... used to be low, but nowadays it has improved and she is continuing to do well and she is reading [emphasis added]... and I am taught not to make noise, because this girl may be having something that is disturbing her, and I don't know what is disturbing her... Here she is called and talked to and she listens. So, I have seen that it has helped us a lot on how to motivate them in their studies, now she is studying and doing her homework [emphasis added].

As a result of the open communication channels, girls have become more open with information to their parents and can easily hold candid conversations without hiding any information from their parents. A parent attending an FGD from Treatment 1 in Viwandani explained:

... Nowadays they don't hide... when she comes she will not hide but tell you, mama it was this and that... Based on how they are taught there, they are taught well on the Saturday... They are taught good things on how they are able to stay and live and to learn.

From the parental narratives, the challenges of slum life have reinforced their belief in the community social capital that they expressed at baseline, in order to sustain the dream for their daughters educational opportunities. Parental guidance and counselling has enhanced parental belief in the potential of their daughters, and has demonstrated that open communication between girls and their parents is critical towards building an academically supportive relationship. Moreover, the parental meetings has enabled them to believe that their daughters can be able to outlive the poverty in the slums, if only each and everyone one of the parents supports the girls in any little way. Parental narratives show that open communication was extended to between parents living within the same community, so as to monitor, mentor and guide girls in the absence of their own parents and guardians. A parent attending an FGD from Treatment 1 in Korogocho said:

... then agree with these parents... when your child is within range of the other parents, and if your child is moving in the wrong direction, she will be called, and made to sit down and be talked to like their own 
child... So, if anything happens to one of the children, and if she cannot tell the parents, your child will come and tell you... You will go to the parent... sit down... with your daughter and talk to her or you give the children the morale to work hard. So, when one wants to do something bad, the others will warn the other, and tell her that you know your mum will know...

The community leaders on their part expressed confidence and satisfaction with the outcome of the parental component of the intervention. They explained that parents have taken it upon themselves to counsel and encourage other parents in order to sustain some of the key messages that they learn at the sessions, particularly on the need to take their daughters to school. The chief of Korogocho explained it in this way.

They also have their own meetings either in groups at the village level to discuss parents who are in one way or the other unable to take the girls to school, or those who do not want to take the girls to school. So, they warn them, encourage them, and tell them what the policy of the government is...

\subsection{Motivation of Girls}

Increased knowledge, motivation and initial indications of change in behaviour among both girls and parents was also observed by parents who were, and whose daughters were exposed to the intervention. Parents appreciated the knowledge that girls had acquired from interacting with mentors in the after-school homework support sessions. They were of the opinion that girls had learned skills that they did not previously know. Moreover, aspects of the skills learned had encouraged girls to think differently, was motivating them in their school work, and to do things differently in the households. A female parents in Korogocho and in a treatment zone 2 had this to say:

... R4: I am grateful because when she came here, she has been taught a lot of things that she didn't know about... R4: And now she knows and this will help her. But, if they had left them alone she wouldn't know anything. So, I am thankful for the start of the project, it is educating our children, it motivates them, and makes them think.

\subsection{Onset of Behavior Change among Girls}

In addition, parents identified specific ways in which tendencies in change of behaviour among girls was occurring as a result of this intervention. This is included and not limited to changes in the company of peers that their daughters kept; girls stopped loitering within the community; those girls who were formerly not obedient to their parents were now more obedient. Therefore, parents registered a great deal of satisfaction with the changes that were being exhibited by their daughters. A parent in attending a FGD in a treatment site in Viwandani explained:

... She has changed the bad company that she had, and she is no longer with them... She has moved to the good company. So, if she is changed like this, even in her studies, she will do well... R3: This tuition helps because the child has no time to loiter, when she leaves tuition she comes to the house to do her homework and she no longer has time for loitering and that has helped a lot... R4: Even mine has changed, in the past, at times, you would send her and she would refuse to go but now she does work well, remembers her homework, and all is well and she is doing very well...

In addition, parents in Viwandani, explained that their daughters had shown a lot of changes in terms of their behavior. They perceived that their daughters' behavior was different as compared to what they had been observing in the previous months. This was attributed to learning received at the after-school support centers. A Parent who was part of an FGD in Viwandani in Treatment 1 explained this initial indications of positive change in behavior in this way:

I have seen that they are changed... based on the education, and how they are progressing, it is not bad. There is a difference in the past months. Even my own child, I see that she has changed; she is not the same she as she used to be...

However, this change of behavior was not evident in the control, in terms of the behavior that had been exhibited by parents in the way they perceived their role in their daughters' education to be. Most of the parents still 
viewed their role as that only limited to paying school fees. This still was the main narrative coming from the parents in the control sites. A female parent in the control sites in Viwa explained:

... let us say that you are unable to pay your child's school fees... So, if she sees she is sent home once, then twice that will be a problem to her. And you know when she is sent home, and stays a while, and by the time she goes back to school the rest have moved on in studies... She is left behind. She will start saying that she has become big and doesn't want to go to school because she is left behind with by her classmates...

Moreover, these parents in the control zone where there was no intervention, thought that the best way in which girls could learn and internalize the importance of education, is through using extended relatives in the family. It was the belief of parents that relatives could impart some knowledge which they may never had the time to, or that they could not easily talk about. A female parent attending a mixed FGD in the control zone in Viwandani explained it in this way:

... The problems that I encounter concerning my daughter; I'd really love for her to stay in school... when she closes school, I advise her to go visit her uncles, those who learnt and are living nice lives. So, that when she leaves there, she comes changed and knows that if she reads and completes school she will have her own car on the road...

\subsection{Acquisition of Knowledge}

Parents in the treatment zone appreciated the knowledge that they had acquired from interacting with the counselors during the counseling sessions. They felt that they had learnt skills that had enabled them to acquire knowledge on various aspects of parenting, and they were empowered as parents to tackle issues affecting their daughters. Moreover, the skills they learnt had enabled the parents to think differently, and motivating them to offer guidance to their daughters so that the girls can feel encouraged to continue with their schooling. This was explained well by parents who had undergone both parental counseling and whose daughters had also attended the after-school support sessions. This is what a parent attending an FGD in Korogocho intimated:

... on my part, I can say this of Miss Korogocho... they have helped a lot... It has taught me on how to stay and talk to girls [emphasis added] whereas previously I did not know. I was very harsh, but since I started coming here, I have learned how to talk to my daughter and she has also known which good words to use. When I was growing up, I didn't know anything... our parents never sat us down and talked to us [emphasis added]. But, I want to praise this project, it has helped my child who is a girl... Parents have been counseled and learned ways of dealing with their daughters [emphasis added]. I thank Miss Korogocho as they have taught me how to stay with a girl child... I have known based on the studies that I have got from here at Miss Korogocho [emphasis added].

\subsection{Positive Attitude the Beneficiaries}

In addition, parents in Korogocho underscored the positive attitude that counseling sessions has instilled in most of them. As a result of the positive attitude, and what they have learnt the parents have begun to advocate for the learning to be extended to other parents within and beyond Korogocho community. The excitement of what parents have learned is motivating them to want to share this information with other parents. This is how the parents described what should happen, as a result of what they have learnt, which has transformed their attitude to being one that is positive towards their daughters' education. This is what a parent in an FGD in the treatment site in Korogocho said:

... And they should teach more parents... We who are here, and have been taught, if you meet another parent who has not been taught yet and is going in a direction that is not understood, be a teacher to her, explain to her and if she does not hear you, later she will sit down and think I was told this by this parent but I did not listen; instead of leaving her as she destroys her home and you sit laughing and badmouthing her, you haven’t helped her in any way.

But this motivation to transform behavior was also to be extended to the girls in both sites. Parents in Korogocho also expressed the need to use what they had learned in the counseling sessions to help trigger change in 
behavior among girls. With the same excitement that they had learned skills in the counseling sessions, parents felt motivated to share this information with their daughters, and daughters of other parents in the same community. This is how a parent echoing the thoughts of other parents described what they should do with the information that they received to trigger change among girls in the community:

... Sit with her and explain it to her, and solve the issue that she has. If it is a neighbor's child, sit with her and talk to her. Also, call her parent and talk to her. Instruct her on the path that she can use to make this child talk. Because you were freely given, you should do the same and give out freely, instead of sitting and not helping out your neighbor, and you sit and laugh at her as her house burns...

The community leaders also appreciated and underscored the positive attitude that was an outcome of the counselling sessions. They observed that as a result of the positive attitude, parents had seen the need to counsel other parents, in order to motivate and encourage them to take their daughters to school. The chief of Korogocho explained it in this way:

They also have their own meetings either in groups at the village level to discuss parents who are in one way or the other unable to take the girls in school or those who do not want to take the girls to school so they warn them, they encourage them and tell them what the policy of the government is...

The thoughts of the community leaders in Koch can be paralleled with the idea that in Viwa the community leaders emphasize on the putting pressure on the parents and other relatives of the girl so that they can be kept in school. We presuppose that if parents in the two communities continue being motivated to encourage other parents to respond to the call of keeping girls in schools, and their leaders pile up the pressure the outcome would be double efforts at keeping girls in school. The chief in Viwandani explains, “... we put more pressure to the parents plus the relatives plus friends who are staying with these young ones, these girls to put more pressure to them so that to at least keep on at least sensitizing them on the advantages of educating the girl child...”

Parental narratives also showed that the outcomes of the intervention in the first year and particularly, among girls who made a transition to secondary school was a great motivator to the current cohort of girls in the intervention. Motivation as an outcome of the intervention was explicitly expressed by parents attending FGDs in Korogocho. In their opinion, the success exhibited by the two organizations-Miss Korogocho and the African Population and Health Research Center (APHRC)—of ensuring that girls who attained 250 marks and above were able to join secondary school. In their view this has been a great motivator to other girls who were still in the program. Parents were optimistic that the current cohort of girls would perform even better. A parent explained:

... I didn't know that my child could join secondary school, because, I didn't have money... But when they called us in the meeting and gave me money... my child is in school and is now studying. I have never seen any other project other than this one by Miss Korogocho, where I got help. ... In this project they came and took our children... and the promises that they made... So, when Miss Korogocho promised them, if they get 250 and above marks... they kept their promise... So, it motivates this current class eight to do much better. Because the other class was doing it just as a trial, but once they got it, the ones that are following them will want to do even much better...

\subsection{Trickling Effect of the Life-Skills and the Counselling within the Community}

Parents and community leaders' narratives also highlighted the intervention was beginning to trickle to the households and other community members. The trickling effect can be attributed to the positive attitudes that both girls and their parents adopted after attending both after-school support and counselling sessions, particularly for those parents who are part of the counselling sessions. Girls transferred the skills that they had learned in the life skills sessions to their siblings in the households. A parent attending an FGD in Viwandani had this to say: “... the way she is taught is the same way I see her teaching the younger one. She tells her we have been taught like this and we are supposed to stay like this..."

The parents also contributed to the trickling effect of the intervention to other parents within the community. Driven by the excitement of what they had learned during the counseling sessions, parents were eager to share with other parents, ways to motivate their daughters, in order to keep them in school. One of the parents attending an FGD in a treatment zone in Korogocho said: 
... And they should teach more parents... We who are here, and have been taught, if you meet another parent who has not been taught yet and is going in a direction that is not understood, be a teacher to her, explain to her and if she does not hear you, later she will sit down and think I was told this by this parent but I did not listen...

The community leaders in Korogocho attested to the strides that have been made in Korogocho in terms of some parents holding meetings and taking time to explain to other parents the importance of this education intervention, and thereby motivating other parents to take their daughters' to school. The community leaders also were in agreement that it is important that parents meet to discuss ways of ensuring that girls attend school. One of the chiefs in Koch said, “... they also have their own meetings either in groups at the village level to discuss parents who are in one way or the other unable to take the girls in school or those who do not want to take the girls to school so they warn them, they encourage them and tell them what the policy of the government is..."

\subsection{Concerted Effort in Support of Girls' Education by All the Stakeholders}

The theme concerted effort in support of girls' education has come out very strongly one year after the onset of the intervention espoused by the community leaders, particularly in Korogocho. At the baseline, parents had pointed out the need for unity of purpose and collaboration in ensuring that girls attend, and continue with school. Consequently they had proposed a multipronged approach—with parents, the community, and teachers forging a close working relationship with their children-if success was to be attained in terms of access to school for girls. One year later the community leaders led by the chief as the gatekeepers of the Korogocho community point out the existence of a concerted effort that goes beyond the existence of Miss Korogocho and APHRC that is keeping a sustained effort to ensure that girls are getting the education they deserve. This is the way in which the chief of Korogocho explained the phenomenon of the concerted effort:

... So, I would like to congratulate APHRC, Miss Korogocho, Ujamaa who is giving loans, the teachers, the community leaders, and also the national administration for becoming actors to ensure that the girls are getting education like any other child...

The parents' narratives also echoed similar sentiments of the community gatekeepers by calling for concerted effort among parents. That parents should be able role model to one another, teach those parents who are yet to internalize the importance of their daughters education. Parents intimated that it is only with parents forming a closely knit group that they can be useful to one another and in turn help their daughters to navigate the challenges of schooling.

Be a role model and show other parents in the right way... And they should teach more parents... We who are here, and have been taught, if you meet another parent who has not been taught yet and is going in a direction that is not understood, be a teacher to her... If it is a neighbor's child sit with her and talk to her. Also, call her parent and talk to her, instructing them on the path that he/she can use to make this child talk. Because, you were freely given (referring to the counseling sessions), you should do the same and give out freely...

The narratives of parents and community leaders also pointed to the need for developing partnership by all the key stakeholders, whether public or private. At the baseline, parents had called for partnerships with the community of parents around the school, nongovernmental organizations, and the government. This was as a result of the prevalent of other problems affecting the education of girls outside the households. The community leaders acknowledge the presence of several actors that have become interested in education of girls. If well managed, this partnership can motivate girls to go beyond primary school.

\section{Discussion}

This paper sought to highlight the perceptions of parents and community members on the additive changes that they are observing among girls and in their respective communities as a result of the intervention. In so doing, the paper sought to answer the following question: What has changed? Parents and community members' perceptions with an education intervention for girls in the slums of Nairobi. The key findings from the paper show that from the community leaders' perspective and parents, there was a general improvement in girls' math and 
literacy one year after the onset of the intervention. In particular, parents note an improvement in math as a result of the after-school support. This corroborates the quantitative results that further shows that the 18.9 percentage difference in math performance between T1 and C groups, in favor of T1, was significant at $10 \%$ level while that between T2 and C groups was 20.2, in favor of T2, was significant at 5\% level. The quantitative findings show that the interventions were clearly helpful in accelerating student mathematics achievement; and more so the component that involves life skills, mentoring and after-school homework support [17].

Moreover, the findings showed that the after-school support sessions have inculcated into the girls a sense of commitment and hard work. Parents gained knowledge about the schooling of girls, and developed a positive attitude towards their daughters. The commitment of girls and the knowledge gained by parents reinvigorated girls effort in school, and ensured that parents were able to pay enough attention to their daughters [17]. This finding particularly coming from parents and the community leaders in the urban informal settlements, shows that in the informal settlements girls' access and commitment to stay in school remains critical [1]. If girls stay on track in school, Kenya inches closer to access to basic education, which at the moment is far from being realized [1]. Moreover, the narratives of the parents show that there was improved communication among the parents and their daughters. Improvement in communication was an outcome of the parental interaction with the counselors during the counselling sessions. Consequently, parents, have been able to effectively talk to their daughters, and avoid being harsh, a phenomenon that was pushing their daughters farther away from them. Open communication has been extended between parents living within the same community, so as to monitor, mentor and guide girls in the absence of their own parents and guardians. Open communication has been noted in the process of monitoring, as parents interact with the program across the two sites. This finding reinforces the finding of similar studies that the existence of parent child communication is important in delivering information not only on education but on sexual health of their children [18]. The study reinforces the notion that when parents communicate openly and clearly [18], crucial messages about education and health may be passed on efficiently. This finding still raises questions in regard to the quality, frequency and timing of this communication between the parents and their daughters. Moreover, effective channels of communication remains one of the greatest lessons learnt in the program, as exhibited by this study. Earlier research had shown the importance of communication in health related interventions. This study shows that education programs can also benefit from rigorous programs that seek to instill parental commitment to education of their children. This commitment has been realized through the encouragement of open communication among the parents and their daughters.

Most importantly, this finding raises fundamental implications for interventions that seek to improve the education of young people, in general and adolescent girls in particular. That it is important to include the families and parents in programs that wish to improve girls' education. This finding also reinforces the importance for starting programs that will constantly seek to support parents to stay involved in their daughters' lives for the improvement of their education and health status. Such programs should then teach young people and their parents to communicate effectively [18] [19].

The findings show that as a result of parental counselling, parents developed a positive attitude towards their daughters and towards girls' education. As a result, parents have taken it upon themselves to counsel and encourage other parents in order to sustain some of the key messages that they learn at the sessions, particularly on the need to take their daughters to school. The positive attitude, and parents wanting to be advocates, is a vital element of sustainability of the project outcomes beyond the duration of the project. Moreover, the skills and knowledge acquired on various aspects of parenting has empowered them to deal with issues affecting their daughters. In this way this intervention has succeeded in creating a participative and interactive learning environment. The content of the materials used during the mentoring and the parental counselling sessions focused on topics relevant to both girls and their parents. This intervention has led to a gradual learning process and thereby a process of empowerment. This is particularly true for parents who may only have primary education and are participating in a self-improving educational activity for the first time in their lives. According to [20], these findings suggest that the very basic of literacy can become useful, meaningful and functional and be transferred to other domains of life and across the communities involved. Moreover, and of most importance, there was an observed trickling effect of the tenets of counseling among parents into the community and the effects of life-skills into the households. On the part of the girls, they transferred the skills that they had learned in the life skills sessions to their siblings in the households. On the part of the parents, they acted as motivators to fellow parents to take their daughters to school. The narratives underscored the existence of a concerted effort among the stakeholders in order to sustain the efforts of ensuring girls get the education they deserve. 


\section{Conclusion}

In conclusion, a year down the line, there are positive perceptions on midterm outcomes of the intervention. The findings show that the knowledge gained by the beneficiaries is gradually leading to an empowerment process within the urban informal settlements, as both girls and their parents become advocates of the program.

\section{References}

[1] Lewin, K. and Little, A. (2011) Access to Education Revisited: Equity, Drop out and Transitions to Secondary School in South Asia and Sub-Saharan Africa. International Journal of Educational Development, 31, 333-337. http://dx.doi.org/10.1016/j.ijedudev.2011.01.011

[2] Republic of Kenya (nd) Education Sector Report. Government Printer, Nairobi.

[3] Hervish, A. and Feldman-Jacobs, C. (2011) Who Speaks for Me? Ending Child Marriage. Policy Brief. Population Reference Bureau, Washington DC.

[4] Lloyd, C. (2013) Education for Girls: Alternative Pathways to Girls Empowerment. A Paper Commissioned by Girl Hub, a Strategic Partnership between Nike Foundation and the UK Department for International Development.

[5] Lewin, M.K. (2009) Access to Education in Sub-Saharan Africa: Patterns, Problems, and Possibilities. Comparative Review, 45, 151-174. http://dx.doi.org/10.1080/03050060902920518

[6] Abuya, B.A., Onsomu, E.O. and Moore, D. (2012) Educational Challenges and Diminishing Safety Net Faced by High-School Girls in a Slum Residence, Nairobi, Kenya. International Journal of Educational Development, 32, 81-91. http://dx.doi.org/10.1016/j.ijedudev.2011.02.012

[7] Rihani, M.A. (2006) Keeping the Promise: Five Benefits of Girls' Secondary Education. Academy for Educational Development, Washington DC.

[8] UNESCO (2012) World Atlas of Gender Equality in Education. UNESCO, Paris. http://books.google.co.ke/books

[9] Ngware, W.M., Abuya, B.A., et al. (2013) Quality and Access to Education in the Urban Informal Settlements in Kenya. APHRC, Nairobi.

[10] Oketch, M., Mutisya, M., Ngware, M. and Ezeh, A.C. (2010) Why Are There Proportionately More Poor Pupils Enrolled in Non-State Schools in Urban Kenya in Spite of FPE Policy? International Journal of Educational Development, 30, 23-32. http://dx.doi.org/10.1016/j.ijedudev.2009.08.001

[11] Admassu, K. (2010) Primary School Completion and Grade Repetition among Disadvantaged Groups: A Challenge to Achieving UPE by 2015. African Population and Health Research Center. http://aphrc.org/wp-content/uploads/2013/11/ERP-III-policy-brief-5.pdf

[12] Sewall-Menon, J., Bruce, J., Austrian, K., Brown, R., Catino, J., Colom, A., et al. (2012) The Cost of Reaching the Most Disadvantaged Girls: Programmatic Evidence from Egypt, Ethiopia, Guatemala, Kenya, South Africa and Uganda. Population Council, New York.

[13] UNESCO (2010) EFA Global Monitoring Report 2010: Reaching the Marginalized. UNESCO, Paris. http://unesdoc.org/images

[14] African Population and Health Research Center (2002) Population and Health Dynamics in Nairobi Informal Settlements. APHRC, Nairobi.

[15] African Population and Health Research Center (2002) Health and Livelihood Needs of Residents of Informal Settlements on Nairobi City. Occasional Study Report 2002. APHRC, Nairobi.

[16] African Population and Health Research Center (APHRC) (2014) Population and Health Dynamics in Nairobi’s Informal Settlements: Report of the Nairobi Cross-Sectional Slums Survey (NCSS) 2012. APHRC, Nairobi.

[17] Abuya, B.A., Ngware, M., Hungi, N., Mutisya, M., Nyariro, M. and Mahuro, G.M. (2014) Community Participation and After-School Support to Improve Learning Outcomes and Transition to Secondary School among Disadvantaged Girls: A Pilot Study in Informal Urban Settlements in Nairobi, Kenya. APHRC, Nairobi.

[18] Wamoyi, J., Fenwick, A., Urassa, M., Zaba, B. and Stones, W. (2010) Parent Child Communication about Sexual and Reproductive Health in Rural Tanzania: Implications for Young People's Sexual Health Interventions. Reproductive Health, 7, 6. http://dx.doi.org/10.1186/1742-4755-7-6

[19] Bastien, S., Kajula, L.J. and Muhwezi, W.W. (2011) A Review of Studies of Parent-Child Communication about Sexuality and HIV/AIDS in Sub-Saharan Africa. Reproductive Health, 8, 25. http://dx.doi.org/10.1186/1742-4755-8-25

[20] Kagitcibasi, C., Goksen, F. and and Gulgoz, S. (2005) Functional Adult Literacy and Empowerment of Women: Impact of a Functional Literacy Program in Turkey. Journal of Adolescent \& Adult Literacy, 48, 472-489. http://dx.doi.org/10.1598/JAAL.48.6.3 